Yan, Y., Han, X., Yang, J., \& Zhou, Q. (2012). On the design of an advanced web-based system for supporting thesis research process and knowledge sharing. Journal of Educational Technology

Development and Exchange, 5(2), 111-124.

\title{
On the Design of an Advanced Web-Based System for Supporting Thesis Research Process and Knowledge Sharing
}

\author{
Yu Yan \\ Xibin Han \\ Juan Yang \\ Qian Zhou
}

Tsinghua University

\begin{abstract}
Recently many universities have adopted web-based systems to manage the supervision and administration of postgraduate programs. The existing web-based systems mainly focus on monitoring the thesis management process rather than on supporting thesis research itself. This study aims on designing an advanced web-based system to support the Master's degree thesis research process and the knowledge sharing. This study firstly identifies the main steps of the thesis research process. It then presents an instructional model based on the analysis of practical thesis research workflow and relevant instructional approaches, such as problem-based learning, cognitive apprenticeship learning and collaborative learning. Based on this instructional model and the relevant literature, six principles were adopted to develop an advanced web-based system for the supporting thesis research process. This system includes three key modules: research process, research group and knowledge sharing. A preliminary evaluation of the system was conducted and the results showed that the system is effective to support the thesis research by providing multi-supervision in the research process. Moreover, a literature resources database plays an important role in knowledge sharing.
\end{abstract}

Keyword: Master's degree thesis, research process, web-based supporting system, knowledge sharing, research group

\section{Introduction}

A thesis or project plays an important role in graduate education in many countries. It is the final achievement before a graduate student may receive a Master's degree. Thesis work requires a significant devotion of time and effort (Harrington, 2009), and represents several capabilities of graduate students, including professional knowledge, research methodology, analytical skills and writing ability (Yan \& Ma, 2008).

In past decades, research concerning the improvement of the quality of thesis supervision and instruction have attracted 
the attention of scholars all over the world. Some of the research focuses on effective thesis instruction offered by the collaboration between librarians, teaching faculty and other writing program staff (Harrington, 2009) or through a mixed committee of both industry professionals and university professors (Host, Feldt, \& Luders, 2010). Others attempt to find out the most effective instruction methods for thesis guidance; for example, Wang, Lin and Long (2008) developed the method of team coaching, which enables students and their advisors to share high quality resources (Wang, Lin, \& Long, 2008). Similarly, Li and Tian (2011) alternatively proposed an "open" graduate thesis guidance mode which can allow advisors and students to communicate across subject areas and improve teacherstudent consultation.

In addition, many researchers are trying to use information technology to facilitate thesis instruction. For example, researchers have suggested using web-based systems to support thesis topic selection (Gutkowski, Wojciechowski, Sakowicz, \& Napieralski, 2007), or using the "Thesis Completion Tool" in the Moodle learning management system to support self-guided learning and instruction under the teacher's supervision (Chen \& Li, 2009).

Also, many universities in China are using web-based systems to support the standard workflow of degree thesis administration and supervision. We investigated some popular thesis management systems in China, such as Change Intelligent Management Platform for Thesis, ZheJiang Online Thesis Management System, Jumu Thesis Management System, and Anhui Television University Graduation Thesis Writing Instructional System. These thesis management systems focus on the work flow of how the thesis is to be completed and monitored, mostly on selecting topics and submitting theses, rather than on supporting thesis research process, and sharing knowledge.
Although little research has been done to deal with the web-based system for supporting thesis process, there are some studies related to improve the students' learning and researching skills using different instructional methods. Problem-based learning (PBL) and collaborative learning are two commonly used learning approaches which can be effectively used together in an online learning environment supported by web-based systems (Wen, 2011). Problem-based learning offers students opportunity to form flexible understanding of knowledge by learning collaboratively (Hmelo-Silver, 2004). A collaborative problem-based learning activity is effective to develop a research culture by encouraging peer-mentoring (Garde-Hansen \& Calvert, 2007), enhancing knowledge acquisition and metacognitive awareness (Raes, Schellens, De Wever, \& Vanderhoven, 2012), and improve critical thinking (Schell \& Kaufman, 2009).

This study will focus on web-based system especially offering degree thesis research process supporting, by combining the problem based learning and collaborative learning approach to enhance the interaction between teachers and students, and support the knowledge sharing in the research process.

This central research question could be divided into four detailed research questions:

1) What are the main steps of Master's degree thesis research process according to existing practical workflows and rules in Chinese universities?

2) What kind of instructional approaches could be used in the main steps according to existing theories and literature? i.e., what is the instructional model for the Master's degree thesis research process? 
3) What kind of web-based system are usable to support the Master's degree thesis research process based on the instructional model? i.e., what kinds of tools or resources should be included or designed in the system to support the thesis instruction?

4) What are the validity and limitations of the web-based system?

The approach applied to answer the research questions is illustrated in Figure1.

\section{The System Analysis}

In this part, we will answer the first two research questions by identifying the main steps and instructional model for the Master's degree thesis research process.

\subsection{Main Steps of the Master's degree Thesis Research Process}

Master's degree thesis research is based on standard thesis management workflow. After analyzing the Master's degree handbooks used in more than 100 Chinese universities, we found that the universities differ in their time management and process organization of the Master's thesis. Despite the differences in detail, most of the thesis research process follows the general standardized steps: thesis topic selection, thesis proposal, process supervision, thesis writing, oral examination, and evaluation of excellent theses.

\subsection{Instructional Model for the Master's degree Thesis Research Process}

Three relevant approaches can be used in the instruction of Master's degree thesis research: problem-based learning, cognitive apprenticeship learning, and collaborative learning.

When a student completes his or her thesis, he or she will follow a research process of problem discovering and problem solving. For thesis research, the student typically follows a problem-based learning (PBL)

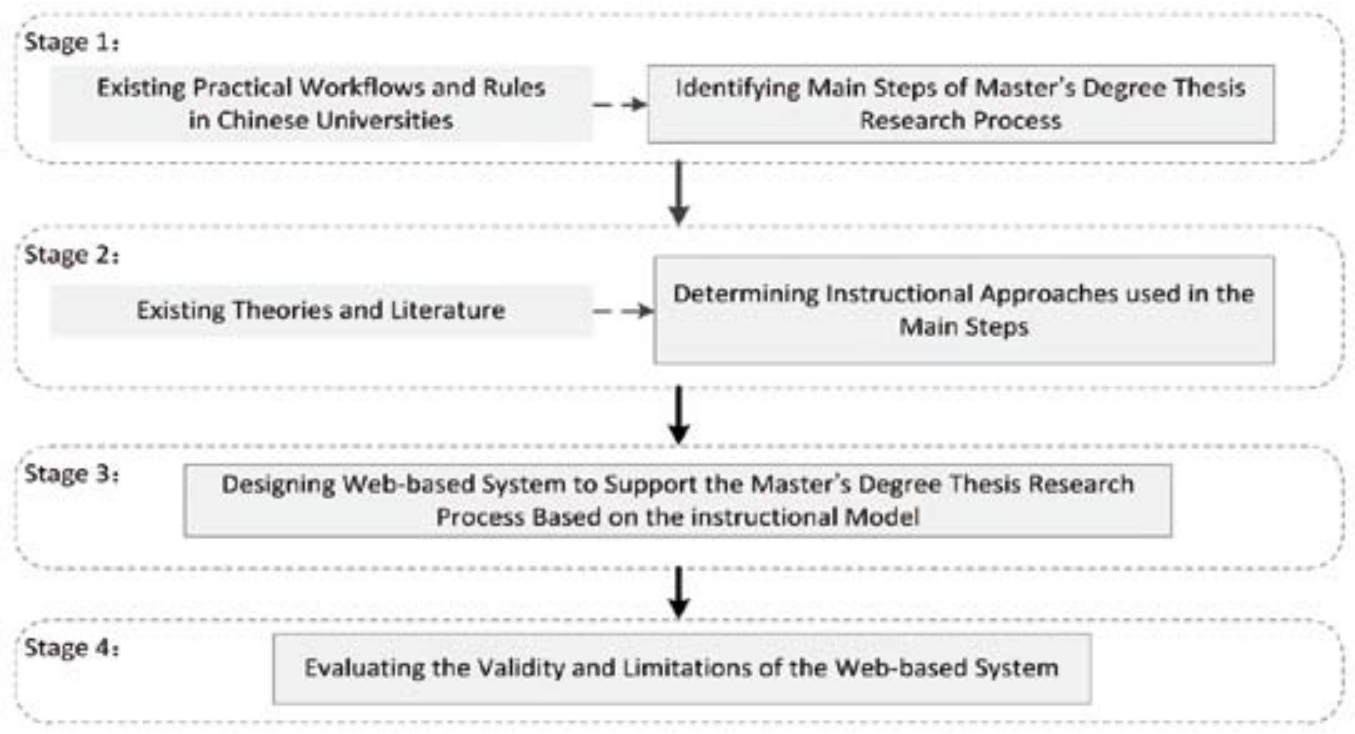

Figure 1. Research approach of this study 
procedure based ondiscovering a problem, analyzing the problem, solving the problem, and evaluating the solution (Marzano \& Kendall, 2008). PBL was originally used in medical case learning but later become widely used by different instructors who wanted to use problems as a "trigger" to encourage students to learn on their own and acquire knowledge (Wood, 2003). The main steps of thesis research and the stages of problembased learning contribute to the real thesis process (Figure 2).

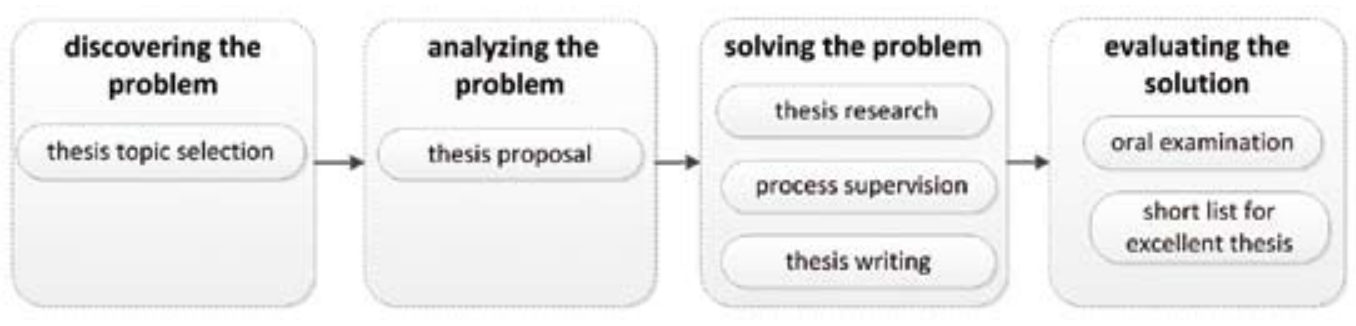

Figure 2. Research process of degree thesis

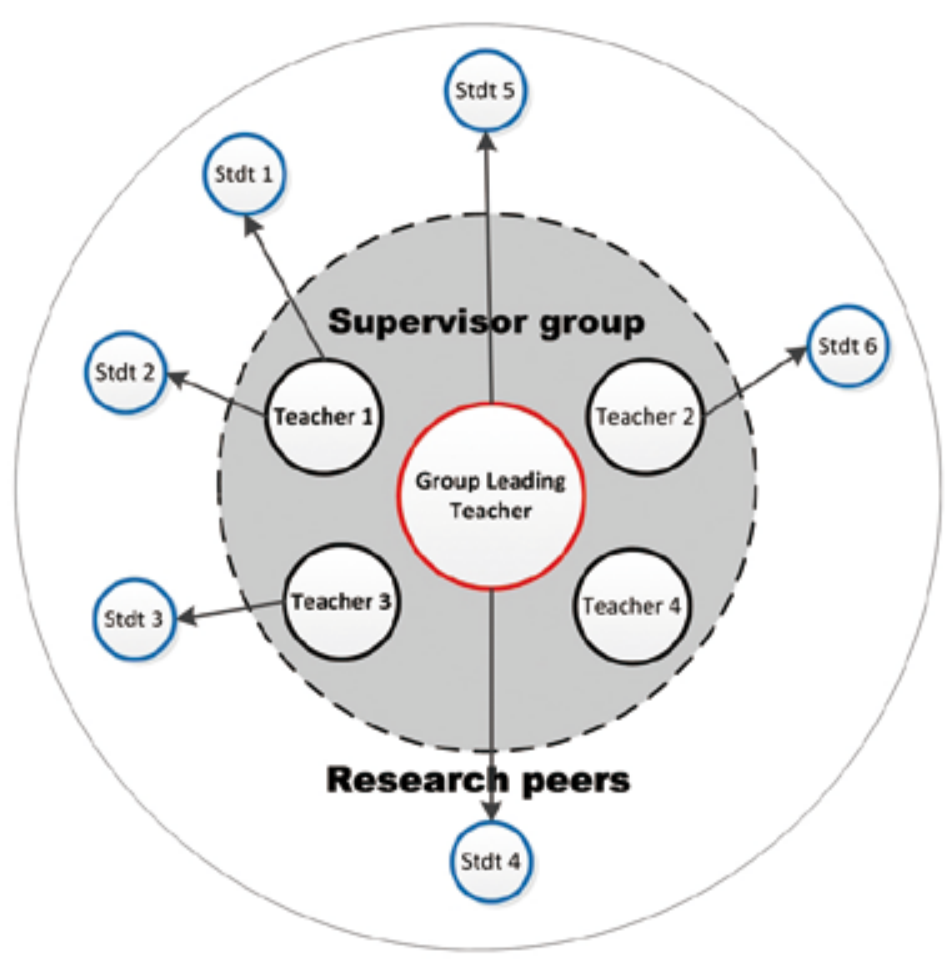

Figure3. Research group 
The real situation in China is that most of the students will choose a topic in the projects they are already engaging in, which is usually designated by their supervisor. This situation leads to a condition where different students work on their own thesis topics which are related to each other if they belong to one research team. Their topics are usually the different sub-issues in the research project. In this case, the whole research group could act as the student's peers or supervisors for thesis research; and the instructional mode of "single student - single supervisor" has its limitations in these situations. The following Figure 3 shows the relations in a project research group. In a research group, there is a leading teacher (in the middle circle) and cooperative teachers, and participating students. The arrows represent the supervisor-student relation. In this research group, all the teachers comprise an instructional group, in which any teacher could instruct any students in the research group. At the same time, all the students in the group are research peers to each other when they are working on their own thesis topics. Lots of research has proven the advantage of the supervisor group.
In the research group, cognitive apprenticeship learning happens when supervisors and students are working on related topics in a research group. Students could follow supervisor closely, not only learning knowledge but also being cultivated scientific spirits. Peering learning enable students to collaborate with each other and learn the team spirits.

The above analysis shows that the research process for the degree thesis needs different type of support from knowledge construction to emotional development, and it could not be confined to one specific instructional approach.

The following Figure 4 shows instructional model for the Master's degree thesis research process. The procedure of the Master's degree thesis research is a combination of problembased learning and thesis management process. The instructional approaches of cognitive apprenticeship and collaboration learning, as well as the grouping method also play vital roles in the whole process.

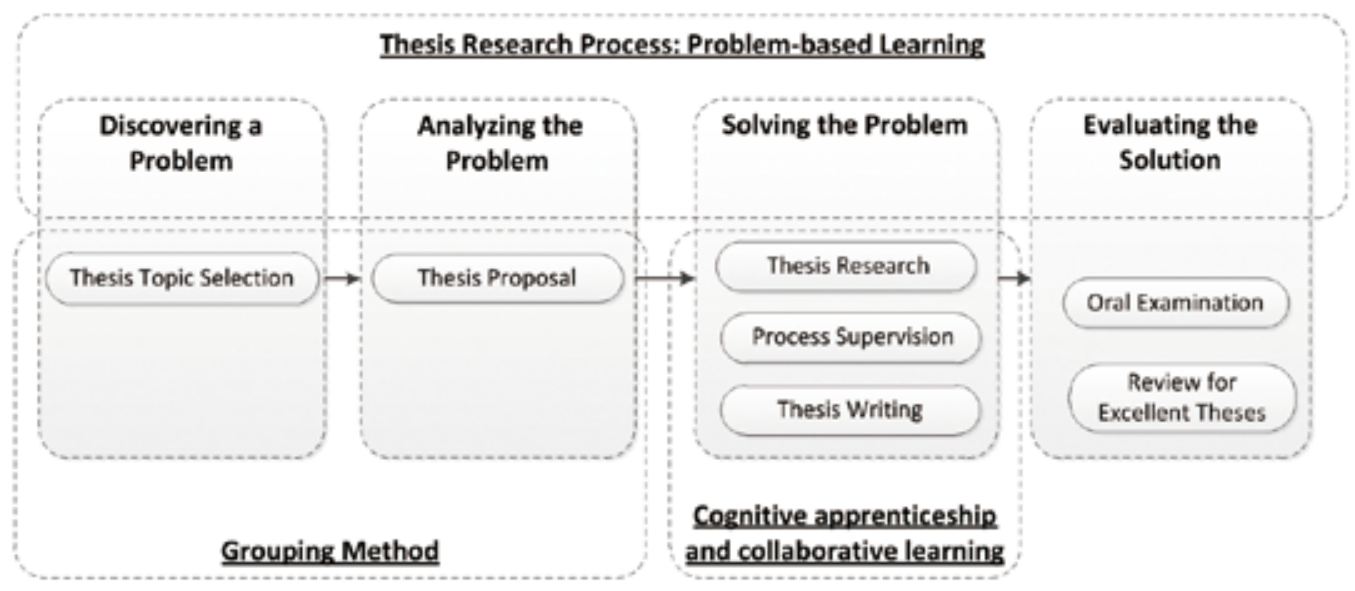

Figure 4. The instructional model for the Master's degree thesis research process 


\section{The System Design}

A web-based supporting system called THEOL is designed according to the instructional model for the Master's degree thesis research process showed in Figure 4. we will discuss the principles for designing the system firstly, then illustrate how the principles are applied to design the system, and finally discuss the functions of key modules in the system.

\subsection{Designing Principles}

According to the above instructional model and the pedagogical software designing principle (Rubens, Emans, Leinonen, Skarmeta, \& Simons, 2005), six principles for designing a web-based system for supporting master degree thesis research process are presented as below.

a) Supporting the whole thesis research process. Since the current system paid much attention on the milestone of thesis writing, the new system, THEOL Thesis system, should focus on the main steps from the discovering the problem to evaluating the solution (shown in Figure 2).

b) Offering group learning environment which enable teacher collaborative instruction. The new software also needs to offer group management supporting the collaborative instruction from supervisor group and collaborative learning among research peers.

c) Facilitating knowledge building rather than just providing a discussion forum (Rubens et al., 2005). The goal for thesis research is to promote knowledge construct. A simple discussion forum is far from effective to encourage the generation of knowledge. Cognitive tools that offer scaffolds or encourage knowledge sharing and ideas publishing should be considered. d) Providing tools for communication and collaboration. Collaboration tools are necessary parts for collaborative learning.

\section{e) Designing tools for process analysis and awareness.}

f) Flexibility and modularity. Education context is different among many universities and locations. Be easy to use and adapting to various conditions is the key feature for an educational software to be usable and flexible.

\subsection{Three Key Modules of THEOL}

The above six designing principles are used to design THEOL thesis system The functionalities of the system are included in three key modules: research process, research group and knowledge sharing. The relationship between these principles and functionalities of three modules are showed in Table 1.

\subsection{The Functions of Key Modules of the System}

The functions of three key modules in THEOL Thesis are designed according to Table 1. In the left top hand of the system interface, there are three buttons including: topic description, research process, and research outcome. These three buttons are the skeleton of problem-based learning. Students are supposed to discover and define their research question in topic description column, organizing and displaying their problem solving process in the research process column. Finally, the students will present their research results (the solution in problem-based learning) in the research outcome part.

Research process module is designed to manage the plan in all steps during whole thesis research process (as shown in Figure 5). Students could make their plans and make note of every litter idea and achievement during daily research. These plans are sharable, which can be commented by other teachers and students. 
Table 1. Relationship between the Designing Principles and Functionalities of Three Key Modules

\begin{tabular}{|c|c|c|c|}
\hline & Research Process & Research Group & Knowledge Sharing \\
\hline $\begin{array}{l}\text { Supporting the } \\
\text { whole thesis } \\
\text { research process }\end{array}$ & $\begin{array}{l}\text { - Organize stage plan } \\
\text { according to thesis work } \\
\text { flow } \\
\text { - Ability to insert and record } \\
\text { any references information } \\
\text { during research process }\end{array}$ & & $\begin{array}{l}\text { - Reference information } \\
\text { could be reached all the } \\
\text { time } \\
\text { - Different kinds of } \\
\text { resources including writing } \\
\text { instructions, reference } \\
\text { articles, degree thesis, etc. }\end{array}$ \\
\hline $\begin{array}{l}\text { Offering group } \\
\text { management } \\
\text { which enable } \\
\text { teachers } \\
\text { collaborative } \\
\text { instruction }\end{array}$ & $\begin{array}{l}\text { - Any teacher in the group } \\
\text { could comments on students' } \\
\text { work } \\
\text { - Personal research process } \\
\text { could be shared in group }\end{array}$ & $\begin{array}{l}\text { - Different ways to } \\
\text { compose the research } \\
\text { group according to } \\
\text { different rules } \\
\text { - Shared group } \\
\text { research achievement } \\
\text { - Flexibility to manage } \\
\text { group members }\end{array}$ & $\begin{array}{l}\text { - Group sharing resources } \\
\text { - Personal resources could } \\
\text { be shared as public }\end{array}$ \\
\hline $\begin{array}{l}\text { Facilitating } \\
\text { knowledge } \\
\text { building rather } \\
\text { than providing } \\
\text { a discussion } \\
\text { forum }\end{array}$ & $\begin{array}{l}\text { - Plug-ins such as } \\
\text { questionnaires and editor } \\
\text { - Teachers recommend } \\
\text { research templates to students } \\
\text { - Save current research process } \\
\text { as template to use next time }\end{array}$ & - Group template & $\begin{array}{l}\text { - Recommendation and } \\
\text { sharing resources } \\
\text { - Comments and mark on } \\
\text { resources }\end{array}$ \\
\hline $\begin{array}{l}\text { Providing } \\
\text { tools for } \\
\text { communication } \\
\& \text { collaboration }\end{array}$ & $\begin{array}{l}\text { - Students and teachers } \\
\text { question and answers } \\
\text { - Plug-ins such as Email, BBS }\end{array}$ & $\begin{array}{l}\text { - Plug-in: group tasks } \\
\text { manager }\end{array}$ & \\
\hline $\begin{array}{l}\text { Designing tools } \\
\text { for process } \\
\text { analysis and } \\
\text { awareness }\end{array}$ & $\begin{array}{l}\text { - Analysis tools could be } \\
\text { conducted during any time } \\
\text { of process } \\
\text { - Different kinds of evaluation } \\
\text { criterion } \\
\text { - News and alert for peers } \\
\text { research process update and } \\
\text { milestone stages }\end{array}$ & $\begin{array}{l}\text { - Group member } \\
\text { shared personal } \\
\text { research process }\end{array}$ & $\begin{array}{l}\text { - Top reading articles rank } \\
\text { - Top comments resources } \\
\text { rank }\end{array}$ \\
\hline $\begin{array}{l}\text { Flexibility and } \\
\text { modularity }\end{array}$ & $\begin{array}{l}\text { - Different templates for } \\
\text { different research topics and } \\
\text { programs } \\
\text { - Pluggable communication } \\
\text { tools }\end{array}$ & $\begin{array}{l}\text { - One teacher could be } \\
\text { in many groups } \\
\text { - Off-campus expert } \\
\text { - Group's own created } \\
\text { templates }\end{array}$ & $\begin{array}{l}\text { resources for person, } \\
\text { research group or public }\end{array}$ \\
\hline
\end{tabular}


Research group module manages the research group. The group leading teacher could build a group and add any teachers or students if necessary. Every group has its own templates and research information data. The personal research achievement and process could be shared among group.
Knowledge sharing module is the reference center for thesis research. writing instructions, reference articles, degree thesis and formal research group's research data, etc.. are all included. It is also a sharing and interactive information center where teachers and students could comments and marks on these resources.

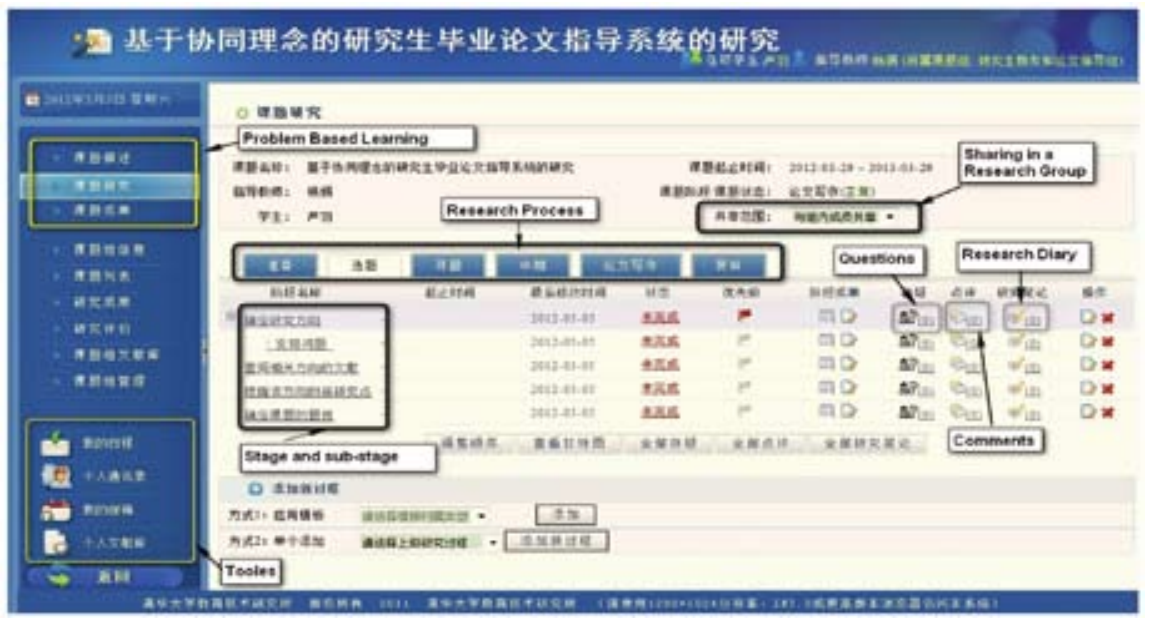

Figure 5. The interface of the research process module

\section{Evaluation of the System}

A preliminary test was designed to evaluate both the technological functionalities and the users motivation with the THEOL Thesis system. The following research questions would be answered:

1) Is the system effective to support the thesis research accordance with the designing principals?

2) Is the system easy to use from the view point of the students?

The first research question is concerned with users' satisfaction with all the functionalities provided by the system to support thesis research. The second question deals with the user friendliness of the software.

There was limited time to take the system into real use. So we managed nine graduate students majored in Educational Technology at Tsinghua University to take the simulation test. These students are in different thesis research stages, from thesis preparation to thesis defending.

The participants were asked to given an overall rating of the system on questions of nine aspects proposed based on six designing principles (see section 3.2). The answers could vary from 1) very agree 2) agree and 3) neutral to 4) disagree 5) and very disagree. The number they gave shown their attitudes to 
the statements such as "I think the system is helpful". Besides, there were also some open questions about their feeling and comments about the system. Such as "are there other comments you want to make to our system?"

\subsection{Result and Discussion}

On the whole, the students gave positive reviews about the system.

Regarding with the support to whole research process, all nine student agreed that the system organized the thesis research process based on the procedure of problembased learning. Eight students agreed that there enough tools to support the whole thesis research process, through Email and comments. However, one student pointed out that his thesis topic shift because his advisor' $\mathrm{s}$ idea changed, and he found the tools cannot support him enough.

The system also acted good in keeping learner's motivation. All students agreed that they were willing to logging in to the system to communicate with teachers and peers and eight of them would like to update their own research process. Some students felt that the online form of communication make them feel "under less pressure" and "more comfortable to communicate". Interesting thing is there was one student who was not likely to update her research process in the system. She commented as "I felt more likely to see what are others doing rather than sharing my own research work". Personality effect the use of the system.

Concerning the teachers' collaborative instruction, all the students agreed that they wished to be supervised by more than one teacher and the system offered this multisupervision. Some students commented like" different teachers give me ideas from different perspective which make me more clear about what I am doing". Students also scored high for the teachers' scaffolding "templates". All the students felt like using the teachers' templates, and five of these students preferred to modify the templates before using. Students felt the templates make them "be more clear about the research methods", "be more effective when doing research". Especially for those who has different backgrounds other than in Educational Technology, the templates "acted like scaffolds and make me find the research direction". However, the score for in-time feedback the system is relative low. Two students hold that there was no real-time communication tools in the system which make real-time feedback not effective. which may due to there was no instant communication tools in two systems. Two students said they will prefer face-to-face talking or phone communication.

Regarding the group management, all the students agreed that they were willing to do research with peers of relevant group. One student even commented "I felt frustrated because there is no other peers in my research group because my topic is so new." Work totally on one's own is not preferred by students anymore.

For the knowledge sharing module in the system, all the students thought that the literature recommendation function improved research efficiency, mostly because "it saved my time for literature searching". However, students kept neutral for that they could quickly find the latest and useful reference resources. Some students comments that "there are little literature information in the system". All the students agreed that former students' research process records helped their current research.

When comes to efficiency of collaboration and communication tools, most students thought the system facilitated the communication between different thesis topics and improving communication frequency between students 
and teachers. Some commented as "Maybe not in the form of online communication, we did communicate with each other more, because we know what others are doing through the system page." However, only half of the students agree that "I usually respond to students' questions and comments". Some students commented as "In this short period of time there is too little opportunities for us to reply very often".

When come to the easy use of the system, half of the students were not satisfied about the interface of the system. The answers to open questions shown that students were sometimes confused by the operating icons in the system and they needed instructions before mastering them.

\section{Conclusions}

In this study we focus on the design of THEOL Thesis system aiming at support thesis research process and offering knowledge sharing.

A significant feature of the Master's degree thesis research process is that it follows a standard thesis research process: thesis topic selection, thesis proposal, process supervision, thesis writing, oral examination, and review for excellent theses.

We combined the instructional approach of problem solving learning within the thesis research process. We also find that research group is effective way to supervise graduates to do their thesis research because it can offer multi-supervision and peers learning. Cognitive apprenticeship and collaborative learning also happened during the thesis research process. We suggest that the following design and develop of this webbased system should continuing combine these learning approaches.

Relevant knowledge produced in the process such as writing instructions, reference articles, degree thesis and formal research group's research data is a necessary part of technology affordances.

THEOL Thesis system was designed and developed according to six principles concerning the thesis research process. The system features three key modules: research process supporting, research group management and knowledge sharing, which have functions to support the whole thesis research process, multi-supervision from the teachers, and rich resource sharing during whole process.

A test with nine student users is designed to evaluate the software prototype of the new system. The result shown that comparing with the old version developed by our team the new system presented in this study is more effective to support the whole thesis research process, and easier to use from the view point of the student users.

This study has its limitations owing to the simulation test with a little amount of participants who used the system for a short time. A real test with enough samples has to be done when the system is put into use. Furthermore, a comparison test could also be made between teachers and the students to see if there is any difference. In addition, the quality of resources produced in research process is the important factor effecting the system's effectiveness. It could be forecasted that the system would be more attractive if it is put in real use in longer time because more valuable research resources will be stored in the system.

\section{References}

Chen, X. H., \& Li, Z. P. (2009). How to Carry out Network Instruction Graduation Thesis by Plugins in Moodle. Software Guide(7), 60-62 Cunningham, D., \& Viola, D. (2002). Collaboration to teach graduate students how to write more effective theses. Journal 
of the Medical Library Association: JMLA, 90(3), 331-4.

Driscoll, M. P. (2005). Psychology of Learning for Instruction: Pearson Education, Inc.

Garde-Hansen, J., \& Calvert, B. (2007). Developing a research culture in the undergraduate curriculum. Active Learning in Higher Education, 8(2), 105116.

Gutkowski, M., Wojciechowski, J., Sakowicz, B., \& Napieralski, A. (2007). Thesis management supporting system based on J2EE platform. Paper presented at the 2007 Proceedings of the 9th International Conference on the Experience of Designing and Application of CAD System in Microelectronics, New York.

Harrington, S. (2009). Librarians and Undergraduate Thesis Support: An Annotated Bibliography. The Reference Librarian, 50(4), 397-412

Hmelo-Silver, C. E. (2004). Problem-Based Learning: What and How Do Students Learn? Educational Psychology Review, 16(3), 235-266.

Host, M., Feldt, R., \& Luders, F. (2010). Support for Different Roles in Software Engineering Master's Thesis Projects. [Article]. IEEE Transactions of Education, 53(2), 288-296.

Li, L., \& Tian, G. (2011). A Study \& Probe into the Guidance Mode of "Open" Graduation Thesis (Project). Theory and Practice of Education, 31(2), 54-55

Liu, Z., Wang, W., Wu, H., \& Zhang, X. (2010). Application of knowledge sharing platform and online collaborative documentation in graduate education. Modern Manufacturing Engineering(5), 107-110

Marzano, R. J., \& Kendall, J. S. (2008). Designing \& assessing educational objectives: applying the new taxonomy: Thousand Oaks : Corwin Press.

Raes, A., Schellens, T., De Wever, B., \& Vanderhoven, E. (2012). Scaffolding information problem solving in web-based collaborative inquiry learning. Computers \& Education, 59(1), 82-94.

Rubens, W., Emans, B., Leinonen, T., Skarmeta, A. G., \& Simons, R. J. (2005). Design of web-based collaborative learning environments. Translating the pedagogical learning principles to human computer interface. [Article]. Computer \& Education, 45(3), 276-294.

Schell, R., \& Kaufman, D. (2009). Critical thinking in a collaborative online PBL tutorial. Journal of Educational Computing Research, 41(2), 155-170.

Wang, L., Lin, J. H., \& Long, J. P. (2008). Study and Practice on the Method of Team Coaching of Thesis of Undergraduates Majoring in Science and Technology. Journal of Chengdu University of Technology (social science), 16(4), 88-91.

Wen, C. K. (2011). When Creative Problem Solving Strategy Meets Web-Based Cooperative Learning Environment in Accounting Education 59(1), 106-118.

Wood, D. F (2003). ABC of learning and teaching in medicine: Problem based learning. BMJ. British medical journal (Clinical research ed.) (09598138), 326 (7384), p. 328.

Yan, H. Z., \& Ma, L. H. (2008). Study on Evaluation Index System of Degree Thesis Based on BPD and AHM. Paper presented at the 2008 IEEE International Sysmposium on Knowledge Acquisition and Modeling Workshop Proceedings, New York. 


\section{Appendix: THEOL Thesis System Survey}

Dear "THEOL Thesis System Survey" participants:

Thank you for using THEOL Thesis System. This is a quick follow-up survey intended to know your using experience and help us enhance the system. Please fill out your basic information and help us to better understand how do you agree with the statements. Scale:

1) Strongly agree, 2) Agree, 3) Neutral, 4) Disagree, 5) Strongly disagree. You can also write your comments on these statements.

Basic information

Gender: $\mathrm{M} \quad \mathrm{F}$

Thesis stage: Preparation ___ ; Topic selection____ ; Thesis writing and defending

\begin{tabular}{ll}
\hline Statements & Rate Comments \\
\hline
\end{tabular}

\section{Support the whole research process}

1 I think the research process is organized based on the procedure of "problem discovering", "problem analyzing", "problem solving" and "solution evaluating"

2 there were various of tools to support the my thesis process Learning motivation

4 I am willing to logging in to the system to communicate with teachers and peers

$5 \quad$ I like to update my own research process frequently

\section{Apprenticeship: teachers' collaborative instruction}

6 I wish to be supervised by more than one teacher

7 The system offers teachers' multi-supervision

8 I can find teachers' comments and answers to my work and questions in the system

9 I feel that this multi-supervision in the form of research group could improve their thesis research efficiency

10 I think the templates offered by teachers are helpful to my research.

11 I am willing to use the teachers' templates

12 I would like to modified the templates before using

13 I can get more in-time feedback information for my thesis research through the system

\section{Group management}

14 I am willing to do research with peers in relevant group

15 I think the communication between teachers and students in research groups become more effective by using the system 


\section{Knowledge construction}

16 I can find the latest and useful reference resources quickly

17 I am happy to share their research process and achievements and discuss them in system

18 I think the literature recommendation function improved my research efficiency

19 I feel that literature comments function fostered a better understanding of the literature itself

20 I think older students' research process records helped their current research

\section{Collaboration and communication tools}

21 I think the system facilitate the communication between different thesis topics

22 The system improved communication frequency between students and teachers

23 I usually respond to students' questions and comments

\section{Process analysis and awareness tools}

24 I can conduct group and personal evaluation during any stage of thesis research

25 I felt process analysis could help them adjust research direction much better

26 I want to see peers' research progress

27 I am aware of other peers' progress easily

28 I usually interested in what other peers doing in my group

\section{Modularity and flexibility}

29 Different templates satisfied my need

30 I can organize my research by using customized columns for thesis description and achievement

\section{User experience}

31 I think the system is easy to use

32 I can easily find the information I need in the system

\section{Open Questions:}

33 Are there other comments you want to make to our system?

34 Are there any other functions you expected from our system?

Thank you for your time and support! 


\section{Contact the Authors}

\section{Yu Yan}

Tsinghua University

Email: appleyanyu@gmail.com

\section{Xibin Han}

Tsinghua University

Email: hanxb@mail.tsinghua.edu.cn

\section{Juan Yang}

Tsinghua University

Email: juan-yang@mail.tsinghua.edu.cn

\section{Qian Zhou}

Tsinghua University

Email: zhouqian@mail.tsinghua.edu.cn 